\title{
Pituitary Function in the Acute Phase of Traumatic Brain Injury and Subarachnoid Hemorrhage
}

\author{
Anna Tölli1 ${ }^{*}$, Jörgen Borg1', Bo-Michael Bellander², Charlotte Höybye ${ }^{3}$ \\ ${ }^{1}$ Department of Clinical Sciences, Karolinska Institutet, Danderyd Hospital, Stockholm, Sweden \\ ${ }^{2}$ Department of Clinical Neuroscience, Section for Neurosurgery, Karolinska Institutet, Stockholm, Sweden \\ ${ }^{3}$ Department of Molecular Medicine and Surgery, Karolinska Institutet and Department of Endocrinology, \\ Metabolism and Diabetology, Karolinska University Hospital, Stockholm, Sweden \\ Email: ${ }^{*}$ anna.tolli@ki.se
}

Received 18 January 2015; accepted 23 June 2015; published 26 June 2015

Copyright (C) 2015 by authors and Scientific Research Publishing Inc.

This work is licensed under the Creative Commons Attribution International License (CC BY).

http://creativecommons.org/licenses/by/4.0/

(c) (i) Open Access

\section{Abstract}

Background: Pituitary insufficiencies after traumatic brain injury (TBI) and subarachnoid haemorrhage (SAH) have been reported with very varying frequencies. The aim of this study was to describe the pituitary function in the acute phase after TBI and SAH in a cohort of adults and relate the results to injury variables. Methods: Adults admitted to the neurointensive care unit in our hospital after moderate and severe TBI or SAH were included prospectively. Demographic, clinical, laboratory, including ACTH stimulation test, and radiological data were collected. Results: A total of 130 adults, 84 (19 women/65 men) with TBI and 46 (38 women/8 men) with SAH were included. Nine patients with TBI and six patients with SAH responded insufficiently to ACTH stimulation; 14 patients with TBI and 9 patients with SAH had low fT4 and low-normal TSH levels. No relations were seen between hormonal levels and injury variables. Conclusions: Pituitary deficiencies occur after TBI and SAH, and a continuous endocrine evaluation of these patients is important. Our study could not define a marker for increased risk for pituitary deficiency. The long-term clinical outcome of the pathological hormone levels in the early phase after TBI and SAH is not known in detail and further studies to elucidate this are needed.

\section{Keywords}

Hormone Disturbance, Pituitary, Traumatic Brain Injury, Subarachnoidal Haemorrhage

\section{Introduction}

Traumatic Brain Injury (TBI) and Subarachnoid Hemorrhage (SAH) with reported annual incidence rates of 235 ${ }^{*}$ Corresponding author.

How to cite this paper: Tölli, A., Borg, J., Bellander, B.-M. and Höybye, C. (2015) Pituitary Function in the Acute Phase of Traumatic Brain Injury and Subarachnoid Hemorrhage. International Journal of Clinical Medicine, 6, 411-422. 
- 506 [1] and 2 - 22 cases per 100,000 inhabitants [2] respectively are major causes of disability and death. Early prediction of long-term outcome is based on a complex interplay between multiple factors including the primary injury and subsequent initiated injury cascade [3], occurrence of secondary insults [4] [5], and acute as well as later neurorehabilitation interventions [6]. Recently, the occurrence and potential impact of pituitary dysfunction has gained increasing interest [7] [8]. Several studies have demonstrated pituitary dysfunction after TBI and SAH but questions remain about the frequency and impact of such dysfunction both in the acute and chronic phase after these events.

Hypopituitarism following TBI [9]-[16] may be isolated, multiple or even total. The prevalence of post-traumatic hypopituitarism (PTHP) varies significantly among studies and ranges from $2 \%$ to 90\% [9]-[17]. Several factors may affect the prevalence of PTHP including the time interval between TBI and investigation of pituitary function, the severity of the injury and the diagnostic tests [8] [17].

Only few studies have reported on hypopituitarism in the acute phase following TBI, such as gonadotropin, adrenal, growth hormone (GH) and thyroidal deficiency [10] [11]. The studies on hypopituitarism following $\mathrm{SAH}$, such as gonadotropin, adrenocorticotrophic (ACTH), GH insufficiency and thyroidal deficiency are also scarce [15] [18]-[22].

In the acute phase multiple factors in addition to the primary injury and the ubiquitous stress response to critical illness may play a role in the development of pituitary deficiencies [23]. For example, the relation between pituitary dysfunction and secondary insults has to be considered. Following TBI and SAH secondary insults [24], such as systemic hypotension, hypoxemia, pyrexia, increasing intracranial pressure (ICP), occur and have been shown to be associated with poor outcome in TBI patients [4] [25] [26] but not in SAH patients [5]. Little is known about the potential impact of such secondary insults on pituitary function and vice versa.

Here we report data on pituitary function in patients with a moderate to severe TBI or an aneurysmal SAH during the initial neurointensive care with regard to the frequency and type of pituitary dysfunction and the relationship to injury variables. We hypothesized that pituitary dysfunction is related to the severity of the primary injury and secondary insults.

\section{Materials and Methods}

We performed a prospective, observational study of patients with moderate or severe traumatic brain injury or subarachnoid haemorrhage. Eligible were patients admitted to the Neurointensive care unit (NICU) at Karolinska University Hospital from March 1, 2009 until June 30, 2012 for TBI or SAH. Patients were included in the NICU and followed up at the Department of Rehabilitation Medicine at Danderyd University Hospital, Stockholm Sweden. Inclusion was not performed during holidays for logistic and administrative reasons. Inclusion required a moderate or severe TBI or SAH due to a ruptured aneurysm, a lowest GCS score during the first day after the event of $3-13$, age $\geq 18$ years, living in the Stockholm region and informed consent. For patients, who were unconscious or otherwise unable to give inform consent, the closest relative was asked. Patients with anticipated fatal outcome were not included. The study was approved by Regional Ethical Review Board in Stockholm (No: 2008/3:9 2008/1574-31/3).

\subsection{Data Collection}

Demographic data (age, sexand smoking status), clinical and radiological parameters were prospectively collected from the NICU medical records and transferred to the study data base.

\subsubsection{Severity Grading}

In addition to the GCS score, clinical severity grading of patients with SAH severity was by the Hunt-Hess scale (HH): 1) asymptomatic or minimal headache, nuchal rigidity; 2) moderate to severe headache, no neurological deficit except for cranial nerve palsy; 3) drowsiness, confusion, mild focal deficit; 4) stupor, moderate to severe hemiparesis, early decerebrate; 5) deep coma, decerebrate posturing, moribund appearance. Aneurysms were verified by computed tomography angiography (CTAI) or digital subtraction angiography (DSA). Aneurysms were divided into aneurysm from the anterior cerebral circulation and the posterior cerebral circulation.

Computed tomography (CT) lesion [27] grading of TBI was according to the CRASH model [28]: presence of one or more petechial haemorrhages (cerebral contusions), obliteration of the third ventricle or basal cisterns, subarachnoid bleed, midline shift $>5 \mathrm{~mm}$, and non-evacuated haematoma (subdural/epidural). Brain oedema, basilar skull fractures and facial fracture were added to the CT model. 
CT lesion grading of SAH was according to Fisher scale (1: no blood detected; 2: SAH less than $1 \mathrm{~mm}$ thick; 3: $\mathrm{SAH}$ more than $1 \mathrm{~mm}$ thick; and 4: intraventricular or parenchymal blood with or without diffuse SAH) [27].

\subsubsection{Assessment of Endocrine Function}

ACTH stimulation test (Synacthene test) and analyses of thyroid function (S-fT4, S-TSH and S-fT3) were performed 10 days post injury or at discharge from NICU, if earlier. The lowest and highest S-osmolality and $\mathrm{P}$-sodium values during this time period were also recorded.

Measurements of S-cortisol, S-fT4, S-fT3, S-TSH, P-Na and S-osmolality were performed at the Department of Clinical Chemistry in Karolinska University Hospital using routine commercial kits and reference data were provided by the department.

ACTH stimulation test was performed by administration of Synacthene $(250 \mu \mathrm{g})$ intravenously and blood samples were drawn before and after 30 minutes for S-cortisol analysis.A normal response to the Synacthene test was defined as S-cortisol at 30 minutes $>550 \mathrm{nmol} / \mathrm{l}$. The patients were divided in three subgroups according to the cortisol response to the Synacthene test; one group with a subnormal response, one group with a cortisol response between 550 and $1000 \mathrm{nmol} / \mathrm{l}$ and one group with a cortisol response $>1000 \mathrm{nmol} / \mathrm{l}$.

Thyroidal dysfunction was defined as fT4 level below the normal reference range concomitantly with normal or low TSH. Reference value for S-TSH: 0.4 - $3.5 \mathrm{mE} / \mathrm{l}$ (DxI) and S-fT4: 8 - 14 pmol/l (DxI).

Reference values for others analysis were; S-fT3: 3.5 - 5.4 nmol/l (Dxl); P-Na: 137 - 145 mmol/l; and S-osmolality 280 - $300 \mathrm{mosmol} / \mathrm{kg}$.

Measurements of gonadotropins, sex-steroids and growth hormone were not included in the evaluation.

\subsubsection{Assessment of Injury Variables and Secondary Insults}

All patients were monitored online using a computerized surveillance system, ICU-pilot ( $\mu$ dialysis, Stockholm, Sweden). Secondary insults were defined according to the Edinburgh University Secondary Insult Grades (EUSIG) [26]. Intracranial pressure (ICP) $>20 \mathrm{mmHg}$, mean arterial blood pressure (MAP) $<70 \mathrm{mmHg}$ and temperature $>38^{\circ} \mathrm{C}$ with a duration exceeding 5 minutes were considered secondary insults.Secondary insults were defined as a deviation from the reference interval lasting for at least 5 minutes. The insults were graded as mild, moderate or severe (Table 1).

\subsection{Statistics}

Statistical analysis was performed using IBM SPSS Statistics version 22 (IBM Corporation, Armonk, New York, USA).

This is an observational study reporting on frequencies as mean \pm SD [range (min-max)] or number (percent) or median (percentile) or median (min-max).

Nonparametric methods were used as data were not normally distributed. The Mann-Whitney U test was used for group comparisons of GCS, Hunt and Hess grade, Fisher grade and peak S-100B (12 - 36 h). The Fisher's exact test was used for comparisons of CT-scan findings, pupil size at admission, pupil reaction to light stimulation at admission. The Kruskal-Wallis test was used for multiple comparisons of ICP, pyrexia, MAP level and hormones. In all cases, significance level was set at $\mathrm{p}<0.05$.

\section{Results}

\subsection{Demographical Data and Injury Characteristics}

A total of 130 patients were included, 84 with TBI and 46 with SAH patients. Two of the included TBI patients

Table 1. Secondary insults at the NICU.

\begin{tabular}{cccc}
\hline & Mild & Moderate & Severe \\
\hline Intracranial hypertension ICP $(\mathrm{mmHg})$ & $20-30$ & $30-40$ & $>40$ \\
Hypotension MAP (mmHg) & $55-70$ & $40-55$ & $<40$ \\
Pyrexia ${ }^{\circ} \mathrm{C}$ & $38-39$ & $39-40$ & $>40$ \\
\hline
\end{tabular}


were 16 years.

Of patients with TBI, 19 were women and 65 men, mean age was $48.3 \pm 16.9$ years, 63 patients had a severe brain injury and 21 patients a moderate brain injury according to the admission GCS score (mean GCS score 6.6 \pm 3.1). Main causes of TBI were falls and traffic accidents. Most common traumatic CT scan pathology were cerebral contusions $(n=65)$, subarachnoidal blood $(n=64)$ and subdural/epidural haematoma $(n=72)$. Data are displayed in Table 2.

Of 46 patients with SAH, 38 were women and 8 men, mean age was $58.3 \pm 10.5$ years, 31 patients had severe and 15 patients a moderate brain injury according to the admission GCS score (mean GCS score $4.4 \pm 3.9$ ). Most frequent Hunt \& Hess scores at admission were 3 and 4. SAH was confirmed by CT scan in all (Fisher grade 2 - 4). Aneurysm location was 34 patients the anterior cerebral circulation (AACC) in 34, the posterior cerebral circulation (APCC) in 9, both anterior and posterior cerebral circulation (AAPCC) in 2, while the aneurysm could not be located in one patient. Data are displayed in Table 3.

\subsection{Endocrine Evaluations}

The endocrine evaluations were performed at day 10 - 15 after TBI or SAH. However, in 25 TBI and 17 SAH patients this was performed day 11 - 15 post injuries. Data were collected between 6.00 and 10.00 am in 49 patents with TBI and 20 patients with SAH, and between 10.00 am and 6.00 pm for the others.

Results from the Synacthene test were available for 77 patients with TBI and for 43 patients with SAH as shown in Table 4. Nine patients (12\%) with TBI and 6 patients (14\%) with SAH (6 AACC) responded with

Table 2. Baseline data of patients with traumatic brain injury (TBI) $(n=84)$.

\begin{tabular}{|c|c|}
\hline & $($ mean \pm S.D.) $(\min -\max )$ \\
\hline Age, years & $48.3 \pm 16.9(16-79)$ \\
\hline BMI & $25.5 \pm 4.9(16.5-42.2)$ \\
\hline \multirow[t]{2}{*}{ GCS } & $6.6 \pm 3.1(3-13)$ \\
\hline & $\mathrm{n}(\%)$ \\
\hline \multicolumn{2}{|l|}{ Gender } \\
\hline Female & $65(77 \%)$ \\
\hline Male & $19(23 \%)$ \\
\hline Smokers & $26(34 \%)$ \\
\hline \multicolumn{2}{|l|}{ GCS } \\
\hline Moderate (9 - 13) & $21(25 \%)$ \\
\hline Severe $(3-8)$ & $63(75 \%)$ \\
\hline \multicolumn{2}{|l|}{ Trauma cause } \\
\hline Traffic accident & $29(35 \%)$ \\
\hline Fall & 47 (56\%) \\
\hline Violence in & $5(6 \%)$ \\
\hline Other & $3(4 \%)$ \\
\hline \multicolumn{2}{|l|}{ CT scan } \\
\hline Cerebral contusions & $65(77 \%)$ \\
\hline Obliteration of the third ventricle or basal cisterns & $24(29 \%)$ \\
\hline Subarachnoid bleed & $64(76 \%)$ \\
\hline Midline shift $>5 \mathrm{~mm}$ & $31(37 \%)$ \\
\hline Subdural/epidural haematoma & $72(86 \%)$ \\
\hline Brain oedema & $16(19 \%)$ \\
\hline Basilar skull fractures & $41(49 \%)$ \\
\hline Facial fracture & 27 (32\%) \\
\hline
\end{tabular}

BMI, Body Mass Index $\left(\mathrm{kg} / \mathrm{m}^{2}\right)$; CT, Computed Tomography; GCS, Glasgow Coma Scale. 
Table 3. Baseline data of patients with subarachnoid haemorrhage (SAH) $(n=46)$.

\begin{tabular}{|c|c|}
\hline & $($ mean \pm S.D.) $(\min -\max )$ \\
\hline Age, years & $58.3 \pm 10.5(28-82)$ \\
\hline BMI & $25.5 \pm 4.5(16.0-36.5)$ \\
\hline \multirow[t]{2}{*}{ GCS } & $7.4 \pm 3.9(3-13)$ \\
\hline & n (\%) \\
\hline \multicolumn{2}{|l|}{ Gender } \\
\hline Female & $38(83 \%)$ \\
\hline Male & $8(17 \%)$ \\
\hline Smokers & $23(51 \%)$ \\
\hline \multicolumn{2}{|l|}{ GCS } \\
\hline Moderate (9 - 13) & $15(33 \%)$ \\
\hline Severe $(3-8)$ & $31(67 \%)$ \\
\hline \multicolumn{2}{|l|}{ Hunter \& Hess grade } \\
\hline 1 & $1(2 \%)$ \\
\hline 2 & $3(6 \%)$ \\
\hline 3 & $16(35 \%)$ \\
\hline 4 & $21(46 \%)$ \\
\hline 5 & $5(11 \%)$ \\
\hline \multicolumn{2}{|l|}{ Fisher grade } \\
\hline 1 & 0 \\
\hline 2 & $3(6 \%)$ \\
\hline 3 & $10(22 \%)$ \\
\hline 4 & $33(72 \%)$ \\
\hline \multicolumn{2}{|l|}{ Aneurysm localisation } \\
\hline \multicolumn{2}{|l|}{ Anterior cerebral circulation AACA } \\
\hline Anterior communicating artery ACoA & $16(35 \%)$ \\
\hline Middle cerebral artery MCA & $14(30 \%)$ \\
\hline Anterior choroidal artery AChA & $2(4 \%)$ \\
\hline Internal carotid artery ICA & $3(7 \%)$ \\
\hline Pericallosal artery & $1(2 \%)$ \\
\hline \multicolumn{2}{|l|}{ Posterior cerebral circulation APCC } \\
\hline Posterior communicating artery PCoA & $5(11 \%)$ \\
\hline Basilar artery & $2(4 \%)$ \\
\hline Vertebral artery & $2(4 \%)$ \\
\hline Posterior inferior cerebellar artery PICA & $2(4 \%)$ \\
\hline
\end{tabular}

subnormal increase in S-cortisol, of whom, 7 patients with TBI and all 6 patients with SAH had been treated with different types of steroids (betamethasone, hydrocortisone, methylprednisolone).

In 27 patients (32\%) with TBI and 23 patients (50\%) with SAH (14 AACC, 7 APCC, and 1 AAPCC) the cortisol response was exaggerated and ranged $1000-2000 \mathrm{nmol} / \mathrm{l}$ or above (one patient with TBI had an exaggerated response of $3300 \mathrm{nmol} / \mathrm{l}$ ). Of patients with exaggerated response, 6 patients with TBI and 3 patients with 
Table 4. Clinical characteristics of TBI and SAH patients in three subgroups of adrenal response.

\begin{tabular}{|c|c|c|c|c|}
\hline & \multicolumn{2}{|c|}{ CORTISOL DYSFUNCTION } & \multicolumn{2}{|c|}{ EXAGGERATED ADRENAL RESPONSE } \\
\hline & TBI $(n=9)$ & SAH $(n=6)$ & TBI $(n=27)$ & $\mathrm{SAH}(\mathrm{n}=23)$ \\
\hline & mean \pm S.D & mean \pm S.D. & mean \pm S.D. & mean \pm S.D. \\
\hline \multicolumn{5}{|l|}{ Cortisol nmol/l } \\
\hline $0 \min (6-10 a m)^{a}$ & $161 \pm 85^{* *}$ & $63 \pm 54 * *$ & $727 \pm 124 * * *$ & $720 \pm 237^{* *}$ \\
\hline $0 \mathrm{~min}(10 \mathrm{am}-6 \mathrm{pm})^{\mathrm{b}}$ & $17 \pm 0$ & $116 \pm 88$ & $721 \pm 330^{* *}$ & $665 \pm 168^{* *}$ \\
\hline $30 \min ^{c}$ & $471 \pm 61^{* * *}$ & $396 \pm 116^{* * *}$ & $1208 \pm 425^{* * *}$ & $1248 \pm 214^{* * *}$ \\
\hline GCS & $7.33 \pm 1.9$ & $7.33 \pm 4.6$ & $5.96 \pm 2.8$ & $7.43 \pm 4.1$ \\
\hline \multirow[t]{3}{*}{ Peak S100B $(12$ - 36 h) $\mu \mathrm{g} / \mathrm{l}$} & $0.61 \pm 0.7$ & $0.36 \pm 0.2$ & $0.58 \pm 0.9$ & $0.83 \pm 3.0^{*}$ \\
\hline & median & median & median & median \\
\hline & (min - max) & $(\min -\max )$ & $(\min -\max )$ & $(\min -\max )$ \\
\hline \multirow[t]{2}{*}{ GCS } & $7(4-11)$ & $6(3-13)$ & $5(3-13)$ & $6(3-13)$ \\
\hline & n (\%) & $\mathrm{n}(\%)$ & n (\%) & n (\%) \\
\hline \multicolumn{5}{|l|}{ Hunt \& Hess } \\
\hline 1 & & $0(0)$ & & $0(0)$ \\
\hline 2 & & $0(0)$ & & $2(9)$ \\
\hline 3 & & $3(50)$ & & $7(30)$ \\
\hline 4 & & $2(33)$ & & $12(52)$ \\
\hline 5 & & $1(17)$ & & $2(9)$ \\
\hline \multicolumn{5}{|l|}{ Fisher grade } \\
\hline 1 & & $0(0)$ & & $0(0)$ \\
\hline 2 & & $0(0)$ & & $2(9)$ \\
\hline 3 & & $0(0)$ & & $5(22)$ \\
\hline 4 & & $6(100)$ & & $16(69)$ \\
\hline \multicolumn{5}{|l|}{ DT scan } \\
\hline Cerebral contusions & $6(67)$ & & $20(74)$ & \\
\hline $\begin{array}{l}\text { Obliteration of the third } \\
\text { ventricle or basal cisterns }\end{array}$ & $3(33)$ & & $10(37)$ & \\
\hline Subarachnoid bleed & 8 (89) & & $20(74)$ & \\
\hline Midline shift $>5 \mathrm{~mm}$ & $1(11)$ & & $12(44)$ & \\
\hline Subdural/epidural haematoma & $8(89)$ & & $24(89)$ & \\
\hline Brain oedema & $4(44)^{*}$ & & $7(26)$ & \\
\hline Basilar skull fractures & $4(44)$ & & $14(52)$ & \\
\hline Facial fracture & $2(22)$ & & $8(30)$ & \\
\hline
\end{tabular}

${ }^{\mathrm{a}}$ Cortisol 6.00 - $10.00 \mathrm{am}$; ${ }^{\mathrm{b}}$ Cortisol $10.00 \mathrm{am}-6.00 \mathrm{pm}$; ${ }^{\mathrm{c}}$ Cortisol response to ACTH. ${ }^{* * *} \mathrm{p}<0.001,{ }^{* *} \mathrm{p}<0.01,{ }^{*} \mathrm{p}<0.05$.

SAH had been treated with different types of steroids (betamethazone, hydrocortisone, metylprednisolone). The cortisol responses (mean values \pm 1 S.D.) to Synacthen in three subgroups are presented in Figure 1.

In the TBI group with an exaggerated cortisol response to Synacthene test, the admission GCS score was non-significantly lower than in TBI patients with a normal or insufficient response as well as compared with $\mathrm{SAH}$ patients from all groups. In for the SAH group with insufficient response to Synachtene, the GCS score was non-significantly lower than in SAH patients with a normal or an exaggerated response as well as compared with TBI patients from all groups. 


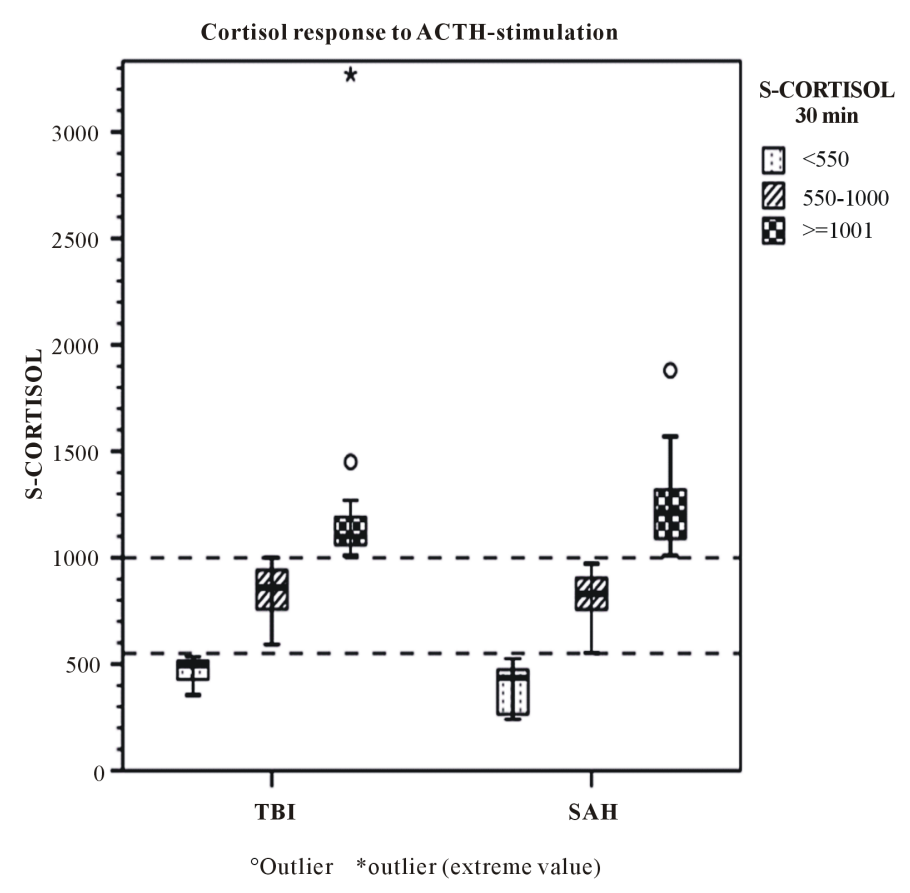

Figure 1. Cortisol response (mean values \pm 1 S.D.) to ACTH stimulation in three subgroups, 10 days after TBI and SAH. Dashed lines illustrate range of normal variation.

There were no differences in the response to Synacthen with or without CT scan pathology except for brain oedema, which was more frequent in SAH patients with a subnormal responses $(\mathrm{p}=0.026)$.

There were no differences between S-cortisol response in patients with SAH or TBI with regard to Fisher grade, Hunter \& Hess grade, pupil size or light reaction. However, a higher peak of S100B (12 - 36 h) [29] was noticed in SAH patients with an exaggerated response $(\mathrm{p}=0.043)$. Data are displayed in Table 4.

Data on thyroid hormones and TSH were available from all patients. Low levels of s-fT4 were found in 18 (22\%) patients with TBI and in 10 (22\%) patients with SAH. Levels of S-TSH were within the normal range in the majority of patients with TBI (13/18) and SAH (6/10). Low levels of S-TSH were found in one patient with TBI and 3 patients with SAH.

In 14 (17\%) patients with TBI and in 9 (20\%) patients with SAH (AACC), a combination of low T4 and low TSH or normal TSH was observed. This was related to the presence of subarachnoid blood on CT scan in TBI patients ( $\mathrm{p}=0.027$ ) but not to GCS score, pupil size, pupil reaction, peak S100B (12 - 36 h), Hunter \& Hess grade or Fisher grade in neither group. Data are displayed in Table 5.

High levels of S-fT4 were noted in 8 (10\%) patients with TBI and in 7 (16\%) patients with SAH (5 AACC, 1 APCC, and 1 AAPCC).We found differences between high level of s-fT4 and peak S100B (12 - 36 h) in SAH patients $(p=0.004)$. Neither were there any differences between high level of s-fT4 and subarachnoid blood $(p=$ $0.044)$ or facial fracture in TBI patients $(p=0.043)$ or between high fT4 and GCS score, pupil size, pupil reaction, Hunter \& Hess grade and Fisher grade. Data are displayed in Table 5.

Low S-fT3 was seen in 26 (32\%) patients with TBI and 19 (42\%) patients with SAH (16 AACC, 2 APCC, and 1 AAPCC). Patients with TBI and low fT3 had lower GCS scores $(p=0.029)$ while no differences were observed between high fT4 and pupil size, pupil reaction, peak S100B (12 - 36 h), DT scan pathology, Hunter \& Hess grade or Fisher grade. Data are displayed in Table 5.

Among TBI patients with a subnormal response to Synacthene test, 5/9 had also low T4 and normal or low TSH and among SAH patients with a sub-normal response to Synacthene test 3/6 had also low T4 and normal or low TSH.

Among TBI patients with an exaggerated cortisol response at the Synacthene test, 1/27 had also low T4 and normal or low TSH and among SAH with an exaggerated cortisol response to the Synacthene test 3/23 had also low T4 and normal or low TSH. 
Table 5. Clinical characteristics of TBI and SAH patients in three subgroups of adrenal response.

\begin{tabular}{|c|c|c|c|c|c|c|}
\hline & \multicolumn{2}{|c|}{$\begin{array}{c}\text { THYROIDAL } \\
\text { DYSFUNCTION }\end{array}$} & \multicolumn{2}{|c|}{ HIGH FT4 } & \multicolumn{2}{|c|}{ LOW FT3 } \\
\hline & TBI $(\mathrm{n}=14)$ & $\mathrm{SAH}(\mathrm{n}=9)$ & TBI $(\mathrm{n}=8)$ & $\mathrm{SAH}(\mathrm{n}=7)$ & TBI $(\mathrm{n}=26)$ & $\mathrm{SAH}(\mathrm{n}=19)$ \\
\hline & mean \pm S.D & mean \pm S.D & mean \pm S.D. & mean \pm S.D. & mean \pm S.D & mean \pm S.D \\
\hline TSH mE/l (DxI) & $1.5 \pm 1.0$ & $1.1 \pm 1.0$ & $1.6 \pm 0.4$ & $1.8 \pm 1.1$ & $1.7 \pm 1.3$ & $2.1 \pm 3.9$ \\
\hline fT4 pmol/l (DxI) & $6.4 \pm 0.8^{* * *}$ & $6.7 \pm 0.5^{* * *}$ & $15.2 \pm 0.5^{* * *}$ & $16.1 \pm 1.3^{* * *}$ & $8.4 \pm 2.5^{* *}$ & $8.7 \pm 2.7^{* *}$ \\
\hline fT3 nmol/l (Dxl) & $3.3 \pm 0.9 * *$ & $3.2 \pm 1.0 * *$ & $4.2 \pm 0.6$ & $3.9 \pm 0.6$ & $2.9 \pm 0.7^{* * *}$ & $3.0 \pm 0.2^{* * *}$ \\
\hline GCS & $7.7 \pm 2.6$ & $6.1 \pm 3.4$ & $7.1 \pm 3.2$ & $9.3 \pm 4.2$ & $7.5 \pm 3.2^{*}$ & $6.5 \pm 3.4$ \\
\hline $\begin{array}{l}\text { Peak S100B } \\
(12-36 \text { h) } \mu \mathrm{g} / \mathrm{l}\end{array}$ & $\begin{array}{c}0.54 \pm 0.6 \\
\text { median } \\
(\min -\max )\end{array}$ & $\begin{array}{c}0.20 \pm 0.1 \\
\text { median } \\
(\min -\max )\end{array}$ & $\begin{array}{c}0.86 \pm 1.0 \\
\text { median } \\
(\min -\max )\end{array}$ & $\begin{array}{c}2.9 \pm 5.7^{* *} \\
\text { median } \\
(\min -\max )\end{array}$ & $\begin{array}{c}0.51 \pm 0.5 \\
\text { median } \\
(\min -\max )\end{array}$ & $\begin{array}{c}0.17 \pm 0.1 \\
\text { median } \\
(\min -\max )\end{array}$ \\
\hline \multirow[t]{2}{*}{ GCS } & $7(4-13)$ & $5(3-13)$ & $6.5(3-13)$ & $11(3-13)$ & $7(3-13)^{*}$ & $6(3-13)$ \\
\hline & n (\%) & n (\%) & n (\%) & n (\%) & n (\%) & n (\%) \\
\hline \multicolumn{7}{|l|}{ Hunt \& Hess } \\
\hline 1 & & $0(0)$ & & $0(0)$ & & $0(0)$ \\
\hline 2 & & $0(0)$ & & $1(14)$ & & $2(10)$ \\
\hline 3 & & $3(33)$ & & $4(57)$ & & $6(32)$ \\
\hline 4 & & $4(45)$ & & $2(29)$ & & $8(42)$ \\
\hline 5 & & $2(22)$ & & $0(0)$ & & $3(16)$ \\
\hline \multicolumn{7}{|l|}{ Fisher grade } \\
\hline 1 & & $0(0)$ & & $0(0)$ & & $0(0)$ \\
\hline 2 & & $0(0)$ & & $0(0)$ & & $1(5)$ \\
\hline 3 & & $1(11)$ & & $1(14)$ & & $4(21)$ \\
\hline 4 & & $8(89)$ & & $6(86)$ & & $14(74)$ \\
\hline \multicolumn{7}{|l|}{ DT scan } \\
\hline Cerebral contusions & $10(71)$ & & $6(75)$ & & $19(73)$ & \\
\hline $\begin{array}{l}\text { Obliteration of the third } \\
\text { ventricle or basal cisterns }\end{array}$ & 4 (29) & & $4(50)$ & & $8(31)$ & \\
\hline Subarachnoid bleed & $14(100)^{*}$ & & $3(38)^{*}$ & & $20(77)$ & \\
\hline Midline shift $>5 \mathrm{~mm}$ & $6(43)$ & & $4(50)$ & & $10(38)$ & \\
\hline Subdural/epidural haematoma & $14(100)$ & & 7 (88) & & $22(85)$ & \\
\hline Brain oedema & $5(36)$ & & $2(25)$ & & $4(15)$ & \\
\hline Basilar skull fractures & $0(0)$ & & $3(38)$ & & $14(54)$ & \\
\hline Facial fracture & $3(21)$ & & $0(0)^{*}$ & & $5(19)$ & \\
\hline
\end{tabular}

${ }^{* * *} \mathrm{p}<0.001,{ }^{* *} \mathrm{p}<0.01,{ }^{*} \mathrm{p}<0.05$

Sixty-three (75\%) of patients with TBI and 40 (90\%) of patients with SAH had P-Na >146 and S-osmolality $>300 \mathrm{mosm} / \mathrm{kg}$. Of these $9 \mathrm{TBI}$ and $9 \mathrm{SAH}$ patients had been treated with fludrocortisone, and 7 patients with TBI and 10 with SAH had been treated with desmopressin.

No differences between high plasma levels of sodium and S-osmolality, and GCS, pupil size, pupil reaction, peak S100B (12 - 36 h), changes on DT scan, Fisher grade, and Hunter \& Hess grade were found.

In 10 (12\%) patients with TBI and in 2 (4\%) patients with SAH a low P-Na in combination with a low S-osmolality was observed. Both patients with SAH lost in weight ( -6.1 to $-1.4 \mathrm{~kg}$ ) while 6 patients with TBI lost weight ( -7.3 to $-1.1 \mathrm{~kg})$ and 4 increased in weight $(+1.5$ to $+7.1 \mathrm{~kg})$.

The number of patients was too few to draw any statistical conclusions. 


\section{Secondary Insults}

The total monitored time possible for analyses of ICP was $243 \pm 183$ hours for TBI patients and $349 \pm 204$ hours for SAH patients. For two patients with TBI monitoring with ICU pilot system could not be done.

Out of 82 TBI patients, 68 patients experienced intracranial hypertension (mild [20 - $29 \mathrm{mmHg}, \mathrm{n}=13$ ]; moderate [30 - $39 \mathrm{mmHg}, \mathrm{n}=23$ ] and severe [ $>40 \mathrm{mmHg} ; \mathrm{n}=32]$ ). In SAH group of 46 patients, 44 patients experiences intracranial hypertension (mild [20 - $29 \mathrm{mmHg}, \mathrm{n}=4$ ]; moderate [30 - $39 \mathrm{mmHg}, \mathrm{n}=16$ ] and severe [>40 mmHg; $n=24]$ ). In patients with TBI, S-fT4 was higher in those with intracranial hypertension when compared with those without intracranial hypertension $(\mathrm{p}=0.045)$ while no other differences of pituitary hormones between these groups were observed.

Out of $84 \mathrm{TBI}$ patients, 75 patients experienced pyrexia (mild $\left[38^{\circ} \mathrm{C}-39^{\circ} \mathrm{C} ; \mathrm{n}=34\right]$; moderate $\left[39^{\circ} \mathrm{C}-40^{\circ} \mathrm{C}, \mathrm{n}\right.$ $=38$ ] and severe [ $\left.>40^{\circ} \mathrm{C} ; \mathrm{n}=3\right]$ ). In $\mathrm{SAH}$ group of 46 patients, 44 patients experiences pyrexia (mild, [ $38^{\circ} \mathrm{C}-$ $\left.39^{\circ} \mathrm{C}, \mathrm{n}=21\right]$; moderate $\left[39^{\circ} \mathrm{C}-40^{\circ} \mathrm{C} ; \mathrm{n}=20\right]$ and severe $\left[>40^{\circ} \mathrm{C} ; \mathrm{n}=3\right]$ ). No differences of pituitary hormones between these groups were observed.

Out of 84 TBI patients, 82 patients experienced low mean arterial blood pressure (MAP) (mild [ $<70$ mmHg; $n$ = 6]; moderate [ $<55 \mathrm{mmHg}, \mathrm{n}=24]$ and severe [ $<40 \mathrm{mmHg} ; \mathrm{n}=52]$ ). All 46 patients with SAH experiences low mean arterial blood pressure (MAP (mild $[<70 \mathrm{mmHg} ; \mathrm{n}=2]$; moderate $[<55 \mathrm{mmHg}, \mathrm{n}=10]$ and severe [ $<40 \mathrm{mmHg} ; \mathrm{n}=34]$ ). No differences of pituitary hormones between these groups were observed.

\section{Discussion}

The study demonstrates that perturbations in the levels of cortisol and thyroid hormones were frequent in the acute phase after TBI and SAH, adrenal and thyroidal functions are often disturbed in the acute phase after TBI and $\mathrm{SAH}$, the most conspicuous findings being the exaggerated response to Synacthene and low thyroid hormones. Additionally, $12 \%$ - $14 \%$ of the patients had a subnormal response to the Synacthene test, and $17 \%-22 \%$ had low circulating thyroid hormones. A specific marker predicting affection of the pituitary function could not be defined, and a clear relation to the severity of the trauma was neither seen.

The reported affection in the acute phase of cerebral trauma on pituitary function has varied in different studies. In 50 patients with moderate to severe brain injury, Agha et al. [10] observed in the acute phase an occurrence of pituitary deficiencies, i.e. adrenal insufficiency (16\%), and thyroidal deficiency (2\%). In the study by Klose et al. [11] pituitary deficiencies with hypothyroidism and hypocortisolism were found in 33 and $4 \%$ of 46 patients during the acute phase after mild to severe TBI. Prasanna et al. [16] observed low levels of GH in $49 \%$, TSH in 45\%, fT4 in $47 \%$, cortisol in $2 \%$ patients one week after moderate to severe TBI.

Regarding SAH, Tanriverdi et al. [15] in 22 patients with SAH observed in the acute phase 23\% deficient on adrenocorticotrophic (ACTH). Furthermore Parenti et al. [19] reported the frequency of pituitary deficiencies in 60 patients during the acute phase after mild to severe SAH and found 7\% ACTH deficiency. Recently Kronvall et al. [20] observed in 51 patients with SAH in acute stage, ACTH deficiency in 8\% and thyrotrophic dysfunction in $6 \%$.

In the present study we found that $12 \%$ of patients with TBI and $14 \%$ of patients with SAH had a sub-normal response to Synacthene test and $17 \%$ and $20 \%$, respectively low T4 and normal or low TSH. Several explanations for the observed differences in prevalence of pituitary deficiencies may be considered. One could be the use of different criteria for the diagnosis of hormone deficiencies in addition to use of different tests. In this study the ACTH deficiency was defined when cortisol response to Synacthene was $<550 \mathrm{nmol} / \mathrm{lat} 30$ minutes. In Klose et al. [11] adrenal insufficiency was defined as $30 \mathrm{~min}$ cortisol $<500 \mathrm{nmol} / \mathrm{l}$ in response to both the ITT (insulin tolerance test) and the Synacthene test. In Tanriverdi et al. [18] ACTH deficiency was indicated when basal cortisol was below $193 \mathrm{nmol} / \mathrm{l}$.

Regarding thyroidal deficiency Agha et al. [10] defined thyroidal deficiency as fT4 level below the normal reference range with low TSH. Other factors potentially influencing on the hormone levels are the physiological reaction to the stress caused by the trauma and the use of glucocorticoids. Probably, a multitude of combinations of all these factors can occur and explain the different frequencies of pituitary dysfunction reported. Interestingly, in this study a majority of patients had the physiologically expected exaggerated response to Synacthene and low levels of circulating thyroid hormones. Anyhow, all studies including our have shown that some patients develop pituitary deficiencies, and therefore the pituitary function in these patients should be evaluated. The impact on clinical long-term outcome of the pathological hormone levels in the early phase after TBI and SAH 
are not known in detail and more studies are warranted.

There are no previous published studies on the relation between secondary insults and pituitary function but theoretically severe or moderate secondary insults would be assumed to impair pituitary function. Despite that a majority of the patients had severe intracranial hypertension, this was associated only with fT4 levels in patients with TBI, which may reflect a physiological reaction to injury severity. Notably, secondary insults were continuously monitored and treated and short duration of secondary insults may have prevented more prominent impact on pituitary function.

\section{Study Limitations}

Patients with TBI and SAH are heterogeneous and many other factors, such as infection, raised intracranial pressure, seizures, vasospasm, arterial hypotension, hypoxemia, pyrexia can potentially affect the hormone levels and the development of secondary injuries. Larger cohorts are needed to control for such other factors.

\section{Conclusion}

In conclusion, this study confirmed that pituitary deficiencies occur in a substantial number of patients early after TBI and SAH, and thus that it is important to evaluate these patients continuously with endocrine examinations. Our study could not define a single marker for increased risk for pituitary deficiency. The long-term clinical impact on outcome of the pathological hormone levels in the early phase after TBI and SAH is not know in detail and further studies to elucidate this are needed.

\section{Competing Interests}

The authors have no competing interests to declare.

\section{Authors' Contributions}

All authors participated in planning the study, data collection, data analyses and writing.

\section{Acknowledgements}

The study was partly funded by a research grant from Pfizer, Sweden. Anna Tölli has received support by grants from Stockholm County Council (ALF-grants).

\section{References}

[1] Tagliaferri, F., et al. (2006) A Systematic Review of Brain Injury Epidemiology in Europe. Acta Neurochirurgica (Wien), 148, 255-268. http://dx.doi.org/10.1007/s00701-005-0651-y

[2] Ingall, T., et al. (2000) A Multinational Comparison of Subarachnoid Hemorrhage Epidemiology in the WHO MONICA Stroke Study. Stroke, 31, 1054-1061. http://dx.doi.org/10.1161/01.STR.31.5.1054

[3] Gaetz, M. (2004) The Neurophysiology of Brain Injury. Clinical Neurophysiology, 115, 4-18. http://dx.doi.org/10.1016/S1388-2457(03)00258-X

[4] McHugh, G.S., et al. (2007) Prognostic Value of Secondary Insults in Traumatic Brain Injury: Results from the IMPACT Study. Journal of Neurotrauma, 24, 287-293. http://dx.doi.org/10.1089/neu.2006.0031

[5] Ryttlefors, M., et al. (2007) Secondary Insults in Subarachnoid Hemorrhage: Occurrence and Impact on Outcome and Clinical Deterioration. Neurosurgery, 61, 704-714. http://dx.doi.org/10.1227/01.NEU.0000298898.38979.E3

[6] Turner-Stokes, L. (2008) Evidence for the Effectiveness of Multi-Disciplinary Rehabilitation Following Acquired Brain Injury: A Synthesis of Two Systematic Approaches. Journal of Rehabilitation Medicine, 40, 691-701. http://dx.doi.org/10.1227/01.NEU.0000298898.38979.E3

[7] Hannon, M.J., Sherlock, M. and Thompson, C.J. (2011) Pituitary Dysfunction Following Traumatic Brain Injury or Subarachnoid Haemorrhage-In "Endocrine Management in the Intensive Care Unit”. Best Practice. Research Clinical Endocrinology. Metabolism, 25, 783-798. http://dx.doi.org/10.1016/j.beem.2011.06.001

[8] Kokshoorn, N.E., et al. (2010) Hypopituitarism Following Traumatic Brain Injury: Prevalence Is Affected by the Use of Different Dynamic Tests and Different Normal Values. European Journal of Endocrinology, 162, 11-18. http://dx.doi.org/10.1530/EJE-09-0601 
[9] Kelly, D.F., et al. (2000) Hypopituitarism Following Traumatic Brain Injury and Aneurysmal Subarachnoid Hemorrhage: A Preliminary Report. Journal of Neurosurgery, 93,743-752. http://dx.doi.org/10.3171/jns.2000.93.5.0743

[10] Agha, A., et al. (2004) Neuroendocrine Dysfunction in the Acute Phase of Traumatic Brain Injury. Clinical Endocrinology (Oxford), 60, 584-591. http://dx.doi.org/10.1111/j.1365-2265.2004.02023.x

[11] Klose, M., Juul, A., Struck, J., Morgenthaler, N.G., Kosteljanetz, M. and Feldt-Rasmussen, U. (2007) Acute and LongTerm Pituitary Insufficiency in Traumatic Brain Injury: A Prospective Single-Centre Study. Clinical Endocrinology, 67, 598-606. http://dx.doi.org/10.1111/j.1365-2265.2007.02931.x

[12] Schneider, H.J., Schneider, M., Saller, B., Petersenn, S., Uhr, M., Husemann, B., et al. (2006) Prevalence of Anterior Pituitary Insufficiency 3 and 12 Months after Traumatic Brain Injury. European Journal of Endocrinology, 154, 259265. http://dx.doi.org/10.1530/eje.1.02071

[13] Kokshoorn, N.E., Smit, J.W., Nieuwlaat, W.A., Tiemensma, J., Bisschop, P.H., Groote Veldman, R., et al. (2011) Low Prevalence of Hypopituitarism after Traumatic Brain Injury: A Multicenter Study. European Journal of Endocrinology, 165, 225-231. http://dx.doi.org/10.1530/EJE-11-0365

[14] Berg, C., Oeffner, A., Schumm-Draeger, P.M., Badorrek, F., Brabant, G., Gerbert, B., et al. (2010) Prevalence of Anterior Pituitary Dysfunction in Patients Following Traumatic Brain Injury in a German Multi-Centre Screening Program. Experimental and Clinical Endocrinology Diabetes, 118, 139-144. http://dx.doi.org/10.1055/s-0029-1225611

[15] Kopczak, A., Kilimann, I., von Rosen, F., Krewer, C., Schneider, H.J., Stalla, G.K. and Schneider, M. (2014) Screening for Hypopituitarism in 509 Patients with Traumatic Brain Injury or Subarachnoid Hemorrhage. Journal of Neurotrauma, 31, 99-107. http://dx.doi.org/10.1089/neu.2013.3002

[16] Prasanna, K.L., Mittal, R.S. and Gandhi, A. (2015) Neuroendocrine Dysfunction in Acute Phase of Moderate-to-Severe Traumatic Brain Injury: A Prospective Study. Brain Injury, 29, 336-342. http://dx.doi.org/10.3109/02699052.2014.955882

[17] Klose, M., Stochholm, K., Janukonyté, J., Lehman Christensen, L., Frystyk, J., Andersen, M., et al. (2014) Prevalence of Posttraumatic Growth Hormone Deficiency Is Highly Dependent on the Diagnostic Set-Up: Results from the Danish National Study on Posttraumatic Hypopituitarism. The Journal of Clinical Endocrinology Metabolism, 99, 101-110. http://dx.doi.org/10.1210/jc.2013-2397

[18] Tanriverdi, F., Dagli, A.T., Karaca, Z., Unluhizarci, K., Selcuklu, A., Casanueva, F.F. and Kelestimur, F. (2007) High Risk of Pituitary Dysfunction Due to Aneurysmal Subarachnoid Haemorrhage: A Prospective Investigation of Anterior Pituitary Function in the Acute Phase and 12 Months after the Event. Clinical Endocrinology, 67, 931-937. http://dx.doi.org/10.1111/j.1365-2265.2007.02989.x

[19] Parenti, G., Cecchi, P.C., Ragghianti, B., Schwarz, A., Ammannati, F., Mennonna, P., et al. (2011) Evaluation of the Anterior Pituitary Function in the Acute Phase after Spontaneous Subarachnoid Hemorrhage. Journal of Endocrinological Investigation, 34, 361-365. http://dx.doi.org/10.1007/BF03347460

[20] Kronvall, E., Valdemarsson, S., Säveland, H. and Nilsson, O.G. (2014) Pituitary Dysfunction after Aneurysmal Subarachnoid Hemorrhage Is Associated with Impaired Early Outcome. World Neurosurgery, 81, 529-537. http://dx.doi.org/10.1016/j.wneu.2013.10.038

[21] Pereira, J.L., Albuquerque, L.A., Dellaretti, M., Carvalho, G.T., Vieira Jr., G., Brochado, V.M., et al. (2013) Pituitary Deficiency after Aneurysmal Subarachnoid Hemorrhage. Clinics, 68, 745-749. http://dx.doi.org/10.6061/clinics/2013(06)04

[22] Kronvall, E., Valdemarsson, S., Säveland, H. and Nilsson, O.G. (2015) High Prevalence of Pituitary Dysfunction after Aneurysmal Subarachnoid Hemorrhage: A Long-Term Prospective Study Using Dynamic Endocrine Testing. World Neurosurgery, 83, 574-582.

[23] Ligtenberg, J.J., Girbes, A.R., Beentjes, J.A., Tulleken, J.E., van der Werf, T.S. and Zijlstra, J.G. (2001) Hormones in the Critically Ill Patient: To Intervene or Not to Intervene? Intensive Care Medicine, 27, 1567-1577. http://dx.doi.org/10.1007/s001340101050

[24] Miller, J.D. and Becker, D.P. (1982) Secondary Insults to the Injured Brain. The Royal College of Surgeons of Edinburgh, 27, 292-298.

[25] Chesnut, R.M., Marshall, L.F., Klauber, M.R., Blunt, B.A., Baldwin, N., Eisenberg, H.M., et al. (1993) The Role of Secondary Brain Injury in Determining Outcome from Severe Head Injury. The Journal of Trauma, 34, 216-222. http://dx.doi.org/10.1097/00005373-199302000-00006

[26] Jones, P.A., Andrews, P.J., Midgley, S., Anderson, S.I., Piper, I.R., Tocher, J.L., et al. (1994) Measuring the Burden of Secondary Insults in Head-Injured Patients during Intensive Care. Journal of Neurosurgical Anesthesiology, 6, 4-14. http://dx.doi.org/10.1097/00008506-199401000-00001

[27] Fisher, C.M., Kistler, J.P. and Davis, J.M. (1980) Relation of Cerebral Vasospasm to Subarachnoid Hemorrhage Visualized by Computerized Tomographic Scanning. Neurosurgery, 6, 1-9. 
http://dx.doi.org/10.1227/00006123-198001000-00001

[28] Edwards, P., Farrell, B., Lomas, G., Mashru, R., Ritchie, N., Roberts, I., et al. (2002) The MRC CRASH Trial: Study Design, Baseline Data, and Outcome in 1000 Randomised Patients in the Pilot Phase. Emergency Medicine Journal, 19, 510-514. http://dx.doi.org/10.1136/emj.19.6.510

[29] Thelin, E.P., Johannesson, L., Nelson, D. and Bellander, B.M. (2013) S100B Is an Important Outcome Predictor in Traumatic Brain Injury. Journal of Neurotrauma, 30, 519-528. http://dx.doi.org/10.1089/neu.2012.2553 